\title{
MODULARIZATION BUSINESS CASE ANALYSIS TOOL: LEARNING FROM INDUSTRY PRACTICES
}

\author{
Jin Ouk CHOI ${ }^{1}$; James T. O’CONNOR ${ }^{2}$ \\ ${ }^{1}$ Iowa State University, Dept. of Civil, Construction and Environmental Engineering, 394 Town \\ Engineering, Ames, IA 50011 \\ ${ }^{2}$ The Univ. of Texas at Austin, Dept. of Civil, Architectural and Environmental Engineering, 1 \\ Univ. Station C1752, Austin, TX 78712 \\ *Corresponding author's e-mail: choi.jinouk@gmail.com
}

\begin{abstract}
Modularization is a method of enhancing project value by exporting a portion of site work to fabrication/assembly shops/yards. Maximizing modularization's benefits, however, is something the industry is still struggling to achieve. To achieve it, the construction industry needs a new modularization business case analysis approach and an associated computational tool. Thus the Construction Industry Institute's (CII) Research Team (RT) 283 has developed a business case process to identify the optimum proportion of work hours to be moved offsite via module scope; the process also identifies the drivers of modularization. An optimal decision-making process is thereby established. Still missing from modularization business case analysis is a tool to support this process. This study develops just such a tool with the support of the CII Modularization Community of Practice. The tool manages information on module project drivers and, to the different parts of a module job, assigns a cost/factor/productivity. In developing the tool, researchers collected existing business case analysis tools from different companies and from the literature. The most suitable elements from these have been incorporated into a new modularization business case analysis tool. The tool identifies the optimum level of work hours to move offsite, providing specific savings, not just an indicative value. The tool, set up in three layers, permits details to be added and can be used, as a project is further developed, at successive phases with increasing rigor. This tool was subsequently reviewed by CII Modularization Community of Practice. This tool, by selecting optimum level of modularization, should help the construction industry maximize the benefits of modularization.
\end{abstract}

\section{KEYWORDS}

Modularization; Modular and offsite construction; Modularization business case analysis; Optimal decision-making process

\section{INTRODUCTION}

The value of a construction project may be enhanced by moving a portion of site work to fabrication/assembly shops/yards. Such a method is known as modularization and it is not new; it has been utilized by the industry for centuries. That modularization is a rising trend, though, has been identified by many studies (Choi 2014; Choi and O'Connor 2014; MBI 2010; McGraw-Hill 
2011; NRC 2009; O'Connor et al. 2013; O'Connor et al. 2014). The trend is due to advancements in Building Information Modelling (BIM), automated manufacturing methods, and Information Technologies (IT). In spite of its increased use, however, modularization has yet to be used to its maximum benefit by the industry. Several reports have tried assessing the modularization business case (Jameson 2007; Wu and Lu 2013), though most of these that are publically available are limited to case studies or lessons learned and/or limited to optimizing local problems.

To obtain maximum benefit, the construction industry needs a new modularization business case analysis approach and an associated computational tool. The Construction Industry Institute's (CII) Research Team (RT) 283 has developed a business case process to identify the optimum proportion of work hours that should be moved offsite via module scope; the process also identifies modularization drivers, thereby resulting in an optimal decision making process. Still missing from the modularization business case analysis, however, is a tool to support this process.

The aim of this paper is to develop a modularization business case tool that supports an optimal decision-making process for modularization. It goes about achieving this aim by relying on collected industry practices and presented CII modularization business case process. This study develops a modularization business case analysis tool, using the support of the CII Modularization Community of Practice (a formal venue for the exchange of knowledge that is useful in planning, designing, and executing modularization among modular experts; currently are approximately 30 members). The tool developed here manages information on module project drivers and assigns a cost/factor/productivity to the different parts of a module job. After laying out the research methodology, this paper presents the modularization business case tool. Later, the paper summarizes, in Conclusions and Recommendations, what was learned from the study and offers recommendations for future research.

\section{METHODS}

This study was conducted through four steps: 1) reviewing the literature review, 2) collecting sample modularization case tools, 3) developing a modularization business case tool, 4) validating findings and 4) drawing conclusions and recommending paths for future research.

The literature review was conducted to collect available information on modularization business case analysis from peer-reviewed publications from major construction engineering and management journals. These included the American Society of Civil Engineers (ASCE) Journal of Construction Engineering and Management, the Journal of Management in Engineering, and AACEI transactions and publically available articles such as McGraw Hill's ENR and Power Engineering. The researchers identified that, surprisingly, no peer-reviewed publications exist on modularization business case analysis. They did identify a few professional reports/articles that attempt to assess modularization business case (Jameson 2007; Wu and Lu 2013). These articles provided excellent findings with detailed lessons. Nonetheless, most of them were limited to optimizing local problems through a sample project.

The authors then collected existing business case analysis tools from different leading companies (two owners and two contractors-CII member companies within CII COP; leading engineering 
and construction companies involved in the capital facilities process worldwide with extensive modular construction experiences). There were commonly considered items, though none of the collected tools had a similar format/structure. The most suitable elements were incorporated into a new modularization business case analysis tool. Third, the modularization business case analysis tool was developed based on identified information from the previous steps and CII RT 283 publications. The publications that provided relevant information on Modularization Business Case Analysis were:

1) Research Summary 283-1, "Industrial Modularization: How to Optimize? How to Maximize?" (CII 2012)

2) Implementation Resource 283-2, "Industrial Modularization: Five Solution Elements" (CII 2013)

3) Research Report 283-11, "Industrial Modularization: How to Optimize? How to Maximize?" (O'Connor et al. 2013)

The tool adopted the steps and modular items from the modularization business case flowchart introduced in Implementation Resource 283-2, "Industrial Modularization: Five Solution Elements (CII 2013)." The tool's details are given below.

The draft of the tool was subsequently reviewed by 1) CII Modularization Community of Practice through discussions in face-to-face meetings and online communications (i.e., emails and conference calls) and 2) The University of Texas of Austin Construction Engineering and Project Management Students. In addition, members from one owner and one contractor took the lead in validating the tool by running it on their own projects and discussing it with their inhouse teams. A great deal of feedback was obtained through this process, leading to improvements. Based on such development, the authors provide recommendations for future research in the Conclusions and Recommendations section.

\section{RESULTS - MODULARIZATION BUSINESS CASE ANALYSIS TOOL}

The modularization business case analysis tool identifies the optimum level of work hours to move offsite while satisfying owner objectives. This tool is envisioned as a simple intelligent form that is completed with varying degrees of details for the major module project drivers and assigns a cost/factor/productivity to the different parts of a module job. It is recommended to run this tool more than three times with different modular extents ( $\%$ modularization) to find the optimal extent which will lead to maximum modular benefits. The concepts of the tool are:

- The tool prompts the addition of data for major Project factors.

- The tool is set up in three layers to allow for additional details.

- User can add data available at that time in the Project.

- The tool is iterative.

- The tool is flexible - further detailed layers can be added.

- The tool provides specific savings, not just indicative value.

The tool consists of five tabs: 1) Introduction, 2) Input, 3) Output, 4) Formulas, and 5) Version Control. This results section follows this sequence (excluding formulas and version control tabs).

\section{Introduction tab}


The Introduction Tab provides five pieces of information: 1) purpose, 2) concept, 3) source, and 4) tool instruction, 5) relevant RT283 Publications and resources. Aside from the tool instruction, the other information is explained above. In tool instruction, the authors provide the general guidelines and instructions, which are as follows:

- Tabs four and five are provided for the tool users who wish to adjust/enhance the tool. These tabs can be navigated by clicking any of the tabs at the bottom of the screen.

- The authors recommend users to read the introduction tab first and enter their modular project data/information into the Input tab.

- Once the Input tab is completed, the user can move to the Output tab to review the analysis results.

- The Output screen provides a summary-level set of cost results along with a comparison of stick build and modular approaches for the input provided.

- Supplemental instructions are provided in each tab for users' information.

- Provided costs and numbers are examples and only for the guidance.

- The authors advise users to consult/discuss with his/her team for the input data.

\section{Input Tab}

As explained above, the tool follows the steps in the modularization business case flowchart developed by CII RT283. The six major modularization business case analysis steps are (Table 1): 0) Project Information, 1) Technically Feasibility Analysis, 2) Schedule Benefits Analysis, 3) Site Survey, 4) Module Yard Survey, and 5) Modularization Drivers. Detailed information on the modularization business case flowchart can be found in CII RT 283 publications (CII 2012; CII 2013; O'Connor et al. 2013) or another of the authors' conference papers to be submitted to the 2015 Modular and Offsite Construction (MOC) Summit.

Along with the steps, the tool is set up in three layers, according to level of detail. Depending on project status or the timing of business case analysis, available data may vary. For the best result, it is recommended to fill out all the data for all levels. However, users may complete the firstlevel questions to obtain the preliminary result. The authors recommend users to begin by inserting data from top to bottom if they are unfamiliar with the modularization business case analysis process or the tool. If, however, users are familiar with the process and the tool, the authors recommend going from right (third-level questions) to left (first-level questions). The authors note that for presentation purposes the Input Tab is, in this paper, broken into multiple tables.

Table 1. Business Case Analysis Steps and First Level Questions

\begin{tabular}{|c|c|c|c|}
\hline Business Case Analysis Steps & \multicolumn{3}{|l|}{ First Level Questions } \\
\hline \multirow[t]{3}{*}{0. Project Info } & \multirow{3}{*}{$\begin{array}{l}0.1 \text { Project Name } \\
0.2 \text { Estimated Stick-built TIC } \\
0.3 \text { Target \% Modular } \\
\end{array}$} & & Project XXX \\
\hline & & $\$$ & $200,000,000.00$ \\
\hline & & $\%$ & $25 \%$ \\
\hline 1. Technical Feasibility Analysis & 1.1 Technically Feasible? & $\mathrm{Y} / \mathrm{N}$ & $\mathrm{Y}$ \\
\hline 2. Schedule Benefits Analysis & 2.1 Expected Schedule Saving by MOD & $\$$ & $400,000.00$ \\
\hline 3. Site Survey & $\begin{array}{l}\text { 3.1 Relative Man-hour }(\mathrm{MH}) \text { Cost at Site } \\
\text { / MH }\end{array}$ & $\$$ & 275.00 \\
\hline \multirow[t]{2}{*}{ 4. Module Yard Survey } & \multirow{2}{*}{$\begin{array}{l}\text { 4.1 Relative MH Cost at Assembly Yard } \\
\text { / MH } \\
\text { 4.2 Relative MH Cost at Fab Yard / MH }\end{array}$} & $\$$ & 66.00 \\
\hline & & $\$$ & 99.00 \\
\hline 5. Modularization Drivers & 5.1 Modularization Benefits & $\$$ & $520,000.00$ \\
\hline
\end{tabular}


Formulas used in Table 1 (First Level Questions) are:

- $(2.1$ Expected Schedule Saving by MOD $)=(2.1 .1$ Expected Schedule Saving $) *(2.1 .2$ Cost per day of Schedule)

- (3.1 Relative $\mathrm{MH}$ Cost at Site / MH) $=(3.1 .1$ Labor Productivity at Site) * (3.1.2 Marginal Cost of Site Construction / MH)

- (4.1 Relative MH Cost at Assembly Yard / MH) $=(4.1 .1$ Labor Productivity at Module Assembly Yard) * (4.1.2 Marginal Cost of Module Assembly / MH)

- (4.2 Relative MH Cost at Fab Yard / MH) $=(4.2 .1$ Labor Productivity at Fabrication Yard) * (4.2.2 Marginal Cost of Fabrication / MH)

- Stick-built Cost on Modularization Portion $=(0.2$ Estimated Stick-built TIC $) *(0.3$ Target \% Modular)

- 5.1 Modularization Benefits = (5.1.1 Safety Benefit $)+(5.1 .2$ Quality Benefit $)+(5.1 .3$ Benefits to Local Community) + (5.1.4 Contingency Benefit) + (5.1.5 Other Expected Benefits)

The tool collects data for computing First-Level Questions into Second-Level Questions (Table 2).

Table 2. Second-Level Questions

\section{Second-Level Questions}

2.1.1 Expected Schedule Savings

2.1.2 Cost per day of Schedule

3.1.1 Labor Productivity at Site

3.1.2 Marginal Cost of Site Construction / MH

4.1.1 Labor Productivity at Module Assembly Yard

4.1.2 Marginal Cost of Module Assembly / MH

4.2.1 Labor Productivity at Fabrication Yard

4.2.2 Marginal Cost of Fabrication / MH

5.1.1 Safety Benefit

5.1.2 Quality Benefit

5.1.3 Benefits to Local Community

5.1.4 Contingency Benefit

5.1.5 Site Indirect Costs Benefit

5.1.6 Risk Benefit

5.1.7 Other Expected Benefits

\begin{tabular}{|c|c|c|}
\hline & 40 & \multirow{2}{*}{$\begin{array}{l}\text { Days } \\
\text { /Day }\end{array}$} \\
\hline$\$$ & $10,000.00$ & \\
\hline & 2.2 & \multirow[b]{2}{*}{ /MH } \\
\hline \multirow[t]{2}{*}{$\$$} & 125.00 & \\
\hline & 1.2 & \multirow{3}{*}{ /MH } \\
\hline \multirow[t]{2}{*}{$\$$} & 55.00 & \\
\hline & 1.5 & \\
\hline$\$$ & 66.00 & $/ \mathrm{MH}$ \\
\hline$\$$ & \multicolumn{2}{|l|}{$100,000.00$} \\
\hline$\$$ & $100,000.00$ & \\
\hline$\$$ & $10,000.00$ & \\
\hline$\$$ & $10,000.00$ & \\
\hline$\$$ & $100,000.00$ & \\
\hline$\$$ & $100,000.00$ & \\
\hline$\$$ & $100,000.00$ & \\
\hline
\end{tabular}

Table 3. Module Cost - Second Level Questions

\section{Second Level Questions - Module Cost}

Additional Installation Cost at Site

Additional Shipping Cost

Additional Fabrication Cost at Fab Yard (Materials. \& Labor)

Additional Module Assembly Cost at Assembly Yard

Additional Engineering Cost

Other Cost for Module

Module Cost

\begin{tabular}{|l|l|}
\hline$\$$ & $41,250.00$ \\
\hline$\$$ & $600,000.00$ \\
\hline$\$$ & $13,090,000.00$ \\
\hline$\$$ & $26,400,000.00$ \\
\hline$\$$ & $5,000,000.00$ \\
\hline$\$$ & $550,000.00$ \\
\hline$\$$ & $45,681,250.00$ \\
\hline
\end{tabular}


*The authors would like to note that the numbers provided (costs, percent, ratio, days, etc.) in this paper are for demonstration purposes only. The authors have provided approximate numbers, not actual ones, due to confidentiality issues. The authors hold that readers gain value from this tool based on its structure and how it calculates.

Formulas used for computing module costs - Second Level Questions (Table 3) are:

- $\quad$ Module Cost $=($ Additional Installation Cost at Site $)+($ Additional Shipping Cost $)+$ (Additional Fabrication Cost at Fab Yard (Material (Mtl.) \& Labor)) + (Additional Module Assembly Cost at Assembly Yard) + (Additional Engineering Cost) + (Other Cost for Mod)

- Additional Installation Cost at Site $=(3.1$ Relative $\mathrm{MH}$ Cost at Site $/ \mathrm{MH})+($ Required Installation Labor (MH) / Ton)

- Additional Shipping Cost $=($ Module Transportation Cost $)+($ Pre-fab Transportation Cost $)+($ Transportation Study Cost)

- Additional Fabrication Cost at Fab Yard (Mtl. \& Labor) = (Structural Steel Quantity Removed from Site) *(1+\% Structural Steel Increase for Mod $) *(($ Cost of Structural Steel $)+($ Required Structural Fabrication Labor $(\mathrm{MH}) /$ Ton $) *(4.2$ Relative MH Cost at Fab Yard / MH)))

- Additional Module Assembly Cost at Assembly Yard = (4.2 Relative MH Cost at Fab Yard / MH) * (Total Module Weight) * (Required Module Assembly Labor (MH) / Ton)

- Additional Engineering Cost $=($ Additional Engineering MH's for Mod $) *($ Engineering costs)

- $\quad$ Other Cost for Mod $=($ Yard Management Cost $)+($ TAX $)+($ Import Duties Cost $)+($ Tran Insurance Cost $)+($ Early Investment Cost (Finance $))+($ Etc. $)$

Third-Level Questions (items) include: Required Installation Labor (MH), Module Transportation Cost, Pre-fab Transportation Cost, Transportation Study Cost, Structural Steel Quantity Removed from Site, Cost of Structural Steel, \% Structural Steel Increase for Modularization, Required Structural Fabrication Labor (MH) / Ton, Total Module Weight, Required Module Assembly Labor (MH) / Ton, Additional Engineering MH's for Module, Engineering costs, Yard Management Cost, TAX, Import Duties Cost, Transportation Insurance Cost, Early Investment Cost (Finance), On-site Historical Recordable Incident Rate (RIR) or Serious Injury Incident Rate (SIIR), Off-site historical RIR or SIIR, Projected RIR or SIIR, Safe Behavior Culture, Hazard Awareness Culture, Non-conformance Reports, Cost of Rework, Site Preparation, Site Temporary Facilities, Site Construction Equipment, Site Environmental Impacts, Site Restoration, Indirect Staff and Supervision, Permit Issues, Environmental Impact, Weather Impacts, Political Risks, etc.

\section{Output Tab}

Once the Input tab is completed, users can move to the Output tab to review the analysis results. The Output screen provides a summary table of cost results along with a comparison chart (Figure 1) of stick-built and modular approaches based on the input provided. In the summary table (presenting only Level 1 and 2 information), the results are grouped by 1) general information (project, site and yard), 2) module costs, 3) modularization benefits, and 4) estimated stick-built total installation cost (TIC), modular project TIC, and total cost savings. To aid users' understanding, the modular versus stick-built differential costs chart is provided. 
However, this comparison chart does not include the modularization benefits (soft costs such as schedule savings, safety, quality benefits, etc.) and just compares the module portion of stickbuilt costs and module cost for direct comparison purposes.

\begin{tabular}{|c|c|c|c|c|c|c|c|}
\hline \multicolumn{4}{|c|}{ Summary Table } & \multicolumn{4}{|c|}{ Modular vs. Stick-built Differential Costs } \\
\hline Project Name & Project $X X X$ & & $2 / 11 / 2015$ & \multirow[b]{2}{*}{$250,000,000.00$} & & & \\
\hline \multicolumn{2}{|c|}{ Estimated Stick-buit TIC } & s & $200,000,000.00$ & & & & \\
\hline \multicolumn{2}{|c|}{ \% Modularization } & $\%$ & $25 \%$ & & & & \\
\hline \multicolumn{2}{|c|}{ Common Site Work } & $\%$ & $75 \%$ & \multirow[b]{2}{*}{$200,000,000.00$} & & & \\
\hline \multicolumn{2}{|c|}{ Technical Feasible } & YIN & $\mathrm{Y}$ & & & & \\
\hline \multicolumn{2}{|c|}{ Relative MH Cost at Site / MH } & s & $275 / \mathrm{MH}$ & & & & \\
\hline \multicolumn{2}{|c|}{ Relative MH Cost at Assembly Yard / MH } & s & $66 / \mathrm{MH}$ & \multirow[b]{2}{*}{$150,000,000.00$} & & & \\
\hline \multicolumn{2}{|c|}{ Relative MH Cost at Fab Yard / MH } & $s$ & $99 / \mathrm{MH}$ & & & & \\
\hline \multicolumn{2}{|c|}{ Stick-built Cost - Common Site Work } & s & $150,000,000.00$ & \multirow[b]{3}{*}{$100,000,000.00$} & & & \\
\hline \multicolumn{2}{|c|}{ Expected Stick-buit Cost - Module Portion } & s & $50,000,000.00$ & & & & \\
\hline \multicolumn{2}{|l|}{ Module Cost } & s & $45,681,250.00$ & & & & \\
\hline \multicolumn{2}{|c|}{ Installation Cost at Site } & s & $41,250.00$ & & & & \\
\hline \multicolumn{2}{|c|}{ Shipping Cost } & s & $600,000.00$ & & & & \\
\hline \multicolumn{2}{|c|}{ Fabrication Cost at Fab Yard (Mtl. \& Labor) } & s & $13,090,000.00$ & & & & \\
\hline \multicolumn{2}{|c|}{ Module Assembly Cost at Assembly Yard } & s & $26,400,000.00$ & $50,000,000.00$ & & & \\
\hline \multicolumn{2}{|c|}{ Engineering Cost } & s & $5,000,000.00$ & & & & \\
\hline \multicolumn{2}{|c|}{ Yard Management Cost } & s & $150,000.00$ & & & & \\
\hline \multicolumn{2}{|c|}{ TAX } & $s$ & $100,000.00$ & - & & & Modular \\
\hline \multicolumn{2}{|c|}{ Import Duties Cost } & s & $100,000.00$ & & Stick & E Etc. & $100,000.00$ \\
\hline \multicolumn{2}{|c|}{ Tran. Insurance Cost } & s & $100,000,00$ & & Built & In Tran. Insurance Cozt: & $100,000.00$ \\
\hline $\begin{array}{l}\text { Earty In } \\
\text { Etc. }\end{array}$ & ost (Finance) & $\begin{array}{l}s \\
s\end{array}$ & $\begin{array}{l}100,000.00 \\
100,000.00\end{array}$ & Expected & Project & II Import Duties Cost & $100,000.00$ \\
\hline & & & & Stick-built & & $=\operatorname{TAX}$ & $100,000,00$ \\
\hline $\begin{array}{r}\text { Modularization } \\
\text { Schedu }\end{array}$ & enefit & $s$ & $\begin{array}{l}920,000.00 \\
400,000,00\end{array}$ & Cost - & $50,000,000,00$ & = Yard Management & $150,000.00$ \\
\hline Modular & efits & s & $520,000.00$ & Module & & \begin{tabular}{|c|c} 
Coot \\
Engineering Cost
\end{tabular} & $5,000.000 .00$ \\
\hline & Safety Benefit & s & $100,000.00$ & Portion & & Module Assembly & \\
\hline & Quality Benefit & s & $100,000.00$ & Stick-built & & Cost at Assembly & $26,400,000,00$ \\
\hline & Benefits to Local Community & s & $10,000.00$ & Cost - & 150,00000000 & Yard & \\
\hline & Contingency Benefit & s & $10,000.00$ & Common & $150,000,000.00$ & I Fabriation Cost at & \\
\hline & Site Indirect Benefit & $\mathbf{s}$ & $100,000.00$ & Site Work & & FabYard (Mti. \& & $13,090,000,00$ \\
\hline & Risk Benefit & s & $100,000.00$ & & & Labor) & \\
\hline & Other Expected Benefits & s & $100,000,00$ & & & "Whipping Cost & $600,000,00$ \\
\hline & & & & & & - Instalation Cost at & 41250.00 \\
\hline Estimated Stic & & s & $200,000,000.00$ & & & Site & 41250.00 \\
\hline Estimated Mod & t TIC & s & $194,761,250.00$ & & & II Stick-built Cost- & $150,000,000000$ \\
\hline Estimated Tot: & & s & $5,238,750.00$ & & & Common Site Work & \\
\hline
\end{tabular}

Figure 1. Output - Summary table and comparison chart (Modular vs. Stick-built differential costs)

\section{CONCLUSIONS AND RECOMMENDATIONS}

Under the support of the CII Modularization Community of Practice, the researchers have developed a modularization business case analysis tool. The tool is envisioned as a simple intelligent form that is completed with varying degrees of details for the major module project drivers and assigns a cost / factor / productivity to the different parts of a module job. Before developing this tool, the researchers reviewed peer-reviewed publications from major construction engineering and management journals and publically available articles. From this review, the researchers identified that no peer-reviewed publications exist that deal with modularization business case analysis. In contrast, the researchers have identified a few professional reports/articles that attempt to assess modularization business cases. However, these articles are limited to optimizing local problems through sample projects. Next, the authors collected existing business case analysis tools from different leading companies and examined commonly considered items. However, none of the collected tools had a similar format or structure. The most suitable elements have been incorporated into a new modularization business case analysis tool. 
The tool manages information on module project drivers and assigns a cost/factor/productivity to the different parts of a module job. The tool identifies the optimum level of work hours to move offsite and provides specific savings, not just an indicative value. This tool, by selecting optimum level of modularization, should help the industry achieve the maximum benefits of modularization.

Research ideas for future research into modularization business case analysis include the following:

- framework for comprehensive optimization to maximize modularization benefits

- in-depth study on modularization business case analysis with numerous case projects to collect best practices and critical success factors

\section{ACKNOWLEDGEMENTS}

The authors wish to thank the CII Modularization COP for their support.

\section{REFERENCES}

Choi, J. O. (2014). "Links between Modularization Critical Sucess Factors and Project Performance." Ph.D. Dissertation, University of Texas at Austin, Austin, TX.

Choi, J. O., and O'Connor, J. T. (2014). "Modularization Critical Success Factors Accomplishment: Learning from Case Studies." Construction Research Congress 2014, 1636-1645.

CII (2012). "Industrial Modularization: How to Optimize; How to Maximize." The University of Texas at Austin: Construction Industry Institute, Austin, TX. RS283-1.

CII (2013). "Industrial Modularization: Five Solution Elements." The University of Texas at Austin: Construction Industry Institute, Austin, TX. IR283-2.

Jameson, P. H. (2007). "Is modularization right for your project?" Hydrocarbon Processing, 4753.

MBI (2010). "Improving Construction Efficiency \& Productivity with Modular Construction." Modular Building Institute, VA.

McGraw-Hill (2011). "Prefabrication and Modularization: Increasing Productivity in the Construction Industry." SmartMarket Report.

NRC (2009). "Advancing the Competitiveness and Efficiency of the U.S. Construction Industry." N. R. C. Committee on Advancing the Competitiveness and Productivity of the U.S. Construction Industry, ed., The National Academies, The National Academies Press, Washington, D.C., 122.

O'Connor, J. T., O'Brien, W. J., and Choi, J. O. (2013). "Industrial Modularization: How to Optimize; How to Maximize." The University of Texas at Austin: Construction Industry Institute, Austin, TX. RR283-11.

O’Connor, J. T., O’Brien, W. J., and Choi, J. O. (2014). "Critical Success Factors and Enablers for Optimum and Maximum Industrial Modularization." Journal of Construction Engineering and Management, 140(6), 04014012.

Wu, Y., and Lu, M. "Modularization Program Execution Optimization on Mega Oil Sands Projects." Proc., 57th Annual Meeting of the AACE International 2013, AACE International, the Authority for Total Cost Management. 